\title{
Clinical patterns and the evolution of relapsing polychondritis based on organ involvement: analysis of 126 Chinese patients
}

\section{Lei Zhang ( $\square$ fcczhangl6@zzu.edu.cn )}

Zhengzhou University First Affiliated Hospital https://orcid.org/0000-0003-4105-0824

\section{Shuang Yun}

Zhengzhou University First Affiliated Hospital

\section{Tiange Wu}

Zhengzhou University First Affiliated Hospital

\section{Yujie He}

Zhengzhou University First Affiliated Hospital

Jinyan Guo

Zhengzhou University First Affiliated Hospital

\section{Lishuai Han}

Zhengzhou University First Affiliated Hospital

Jiameng Lu

Zhengzhou University First Affiliated Hospital

\section{Xiaojun Liu}

Zhengzhou University First Affiliated Hospital

\section{Rui Yang}

Zhengzhou University First Affiliated Hospital

\section{Shitao Zhang}

Zhengzhou University First Affiliated Hospital

\section{Tianfang Li}

Zhengzhou University First Affiliated Hospital

\section{Shengyun Liu}

Zhengzhou University First Affiliated Hospital

\section{Research article}

Keywords: Relapsing polychondritis, RPC, clinical pattern, classification, diagnosis

Posted Date: February 25th, 2020

DOI: https://doi.org/10.21203/rs.2.24348/v1 
License: (c) (i) This work is licensed under a Creative Commons Attribution 4.0 International License. Read Full License 


\section{Abstract}

Objective To explore the clinical patterns of relapsing polychondritis(RPC) to improve clinicians' comprehensive understanding of the disease.

Methods The electronic records of RPC patients that were hospitalized and followed-up by rheumatologists at our hospital between January 1, 2008 and August 31,2019 were retrospectively analyzed.

Results Sixty-six males and 60 femaleswere included with onset age of $47.1 \pm 13.8$ years and followed up for a median of 18 months. Eighty-seven patients (69.1\%) did not met with the traditional criteria.Correlation analysis revealed a strong negative correlation between airway involvement and auricular chondritis $(r=-0.75 \llbracket \mathrm{P}<0.001)$. Four distinct clinical patterns were identified: Ear pattern $(50.8 \%)$, Airway pattern (38.9\%), Overlap pattern (4.8\%) and Airway-Ear negative pattern (5.6\%) and patients with Ear pattern and Airway pattern were subdivided as limited and systemic form of RPC (27.8\%with limited form of Ear pattern and $24.6 \%$ with limited form of Airway pattern). During follow-up, a small part of patients with Ear pattern and Airway pattern progressed into Overlap pattern andsome Airway-Ear negative patternpatients progressed into Ear pattern. Most of the limited RPC patientsremained limited form during follow-up whilesome patients with limited form progressed into systemic form. Patients with Ear pattern had the highest survival rate and relative lower inflammatory status.

Conclusion RPC patients can be categorized as 4 differentclinical patterns and 2 distinct presenting forms (limited and systemic) based on organ involvement.Limited form of RPC is not uncommon in Chinese patients and traditional criteria of RPC are not suitable for early diagnosis.

\section{Backgroud}

Relapsing Polychondritis (RPC) is a systemic inflammatory disorder of unknown etiology and characterized by recurrent and progressive inflammation of the cartilaginous structures, particularly involving the auricles, nose and respiratory tract, as well as extra-cartilaginous tissues, including eyes, heart, skin, central nervous and hematological systems[1-3].

The incidence of RPC was estimated to be 3.5 per million per year in the U.S. [4]and 0.71 per million population per year between 1990 and 2012 in the UK[5]. Patients may visit physicians at different departments, mainly non-rheumatologic specialists[5-8], due to protean manifestations and wax and wane disease courses of RPC, and often experience a misdiagnosis[6-8], leading to delayed diagnosis[513].

Because of the rarity of the disease, the diagnosis is mainly based on traditional criteria empirically proposed by McAdams et al.[14] or Damiani et al. [15] and Michet et al.[16]. However, these criteria easily miss patients at early stage because of the inadequacy of clinical manifestations[8]. Meanwhile, partial RPC has been reported by Mathew et al. [11] and our previous study[6] , and limited RPC is not 
uncommon in clinical settings as demonstrated by our previous study [6] and case reports [17-24]. As a result, these patients do not meet with the current criteria. Furthermore, the insufficient disease awareness of physicians, especially of non-rheumatologic specialists, at least partially contributes to diagnostic delay and misdiagnosis[6,25,26]. Thus, clinical pattern analysis of RPC patients, especially of patients in early stage as well as partial and limited RPC, may assist clinicians to bear a comprehensive disease picture in mind, which subsequently may help to improve diagnostic strategy. Although Dion et al.[27] and Shimizu et al.[28,29] have made such attempts, however, these two studies included neither RPC patients in early stage nor partial or limited RPC patients. Therefore, we conducted this study aiming at defining distinct clinical patterns based on organ involvement using our own cohort which included early PRC patients as well as partial and limited RPC patients. In addition, we described the evolution of clinical patterns for the first time.

\section{Methods}

Study population

We retrospectively reviewed the medical records of 126 RPC patients that were hospitalized and followed-up by rheumatologists at our hospital between January, 2008 and August, 2019. RPC was defined according to the criteria proposed by Michet et al.[16] and Damiani et al.[15]. Patients that underwent recurrent chondritis associated with deformity, in accompany with vestibular dysfunction, ocular inflammation, or inflammatory arthritis were diagnosed as partial RPC as suggested by Mathew et al. [11]. Limited RPC can also be diagnosed if patients presented with recurrent inflammatory episodes at isolated cartilaginous sites after exclusion of other possible causes and are responsive to glucocorticoids, based on the observations by other groups and our own $[8,13,17-24]$ and our own experience. Patients younger than 18 years or without complete electronic case files were excluded. Patients with positive anti-neutrophilic cytoplasmic antibody (ANCA) against proteinase-3 (PR3) were also excluded as suggested by Piette and colleagues [30]. The diagnosis was carefully evaluated and jointly established by a group of rheumatologists and physicians in other specialties.

This study was approved by the Ethic Committee of Zhengzhou University (SR-2018-LW-050) and was conducted in accordance with the Declaration of Helsinki.

Statistical Analysis

Descriptive statistics were used to describe demographic and disease characteristics, and all results were expressed as mean \pm standard deviation (SD), median (range) or percentage (\%) where appropriate. Continuous variables were compared using Student's t-test where the data had normal distribution or Wilcoxon rank sum test where the data were not normally distributed. Categorical variables were compared using Fisher's exact test or chi-square test, if appropriate. Correlation analysis was performed to disclose the correlation between organ involvement and correlation coefficients were calculated. A correlation coefficient $r>0$ represents positive correlation and $r<0$ represents negative correlation. Survival rates over time were plotted using the Kaplan-Meier method and compared by log rank test. A two-sided 
P-value $<0.05$ was considered to be statistically significant. Statistical analyses were performed using the SPSS version 17.0 software package (IBM).

\section{Results}

\section{Patient characteristics.}

The current study included 66 male and 60 female patients with age of $47.1 \pm 13.8$ years at disease onset. The age of male patients was comparable to female patients at disease onset ( $46.1 \pm 13.7$ vs $48.1 \pm 13.8$, $\mathrm{P}=0.408$ ). Median duration of follow-up after diagnosis was 18 months (range 1-153 months), with 34 patients followed up for at least 36 months, 51 patients for at least 24 months and 82 patients for at least 12 months. One patient with airway involvement was lost after 2 months follow-up. Median disease duration since disease onset was 26 months (range 3-162 months). Median diagnostic delay was 5 months (range 0-132 months), and 31 patients were delayed for over a year.

When diagnosis was established, 39 patients (30.9\%) met with the traditional criteria, 27 patients $(21.4 \%)$ met with partial RP, while 55 patients (43.7\%) met with limited RP. However, there were still 5 patients $(4.0 \%)$ that did not meet either of these patients, with 1 patient presented auricular chondritis and cardiac involvement, 3 patients presented airway involvement and cardiac involvement and 1 patient presented airway involvement and intracranial aneurysm.

One hundred and seventeen patients (92.9\%) were initially admitted by non-rheumatologic specialists (55 patients by nose, and throat [ENT] specialists, 42 patients by pulmonologists and the rest 20 patients by other specialists [detailed in Supplementary Figure S1]) whereas only 9 patients (7.1\%) by rheumatologists. Ninety-five patients (75.4\%) were misdiagnosed initially, all by non-rheumatologic specialists (including 43 patients by ENT specialists and 35 patients by pulmonologists), and 65 (68.4\%) of these patients received their final diagnosis from rheumatologists while 30 patients (31.6\%) received the final diagnosis from non-rheumatologic specialists. Patients admitted by non-rheumatologic specialists had increased odds for misdiagnosis (Odds Ratio [OR] $=1.4,95 \%$ confidence interval[ $[95 \% \mathrm{Cl}]$ $1.1-1.8, P<0.001)$.

\section{Clinical Features}

The most frequent initial features included auricular chondritis $(n=70,55.6 \%)$ and airway involvement $(n=54,42.9 \%)$ (including 17 patients[13.5\%] with laryngeal involvement and 48 patients[38.1\%] with tracheobronchial involvement), ocular inflammation ( $n=25,19.8 \%)$, fever $(n=20,15.9 \%)$, nasal chondritis $(n=15,14.3 \%)$, arthritis $(n=16,12.7 \%)$, hearing loss $(n=12,9.5 \%)$, cardiac involvement $(n=8,6.3 \%)$, costochondritis ( $n=3,2.4 \%)$, neurological involvement $(n=6,4.8 \%)$, cutaneous manifestations $(n=1,0.8 \%)$, and myelodysplastic syndrome $(n=1,0.8 \%)$ (Figure 1). More features developed at the time of diagnosis and during follow-up, which were detailed in Figure 1 and Supplementary Table S1. Much attention should be paid to that some features remained stable during follow-up, indicating no disease progression in these patients. 
At the last follow-up, airway involvement was found in 60 patients (47.7\%), among them, 19 patients (15.1\%) presented with laryngeal involvement and 51 patients $(40.5 \%)$ with tracheobronchial involvement, indicating 10 patients with both laryngeal and tracheobronchial involvement (Supplementary Table S1).

Neurological involvement was seen in 6 patients (4.8\%), and no new onset of neurological impairment was observed during follow-up. One patient with rapture of intracranial aneurysm (anterior communicating artery) received surgical procedures. Four patients presented psychiatric symptoms, and 1 patient with headache and diplopia, and the Magnetic Resonance Imaging (MRI) of these 5 patients revealed ischemia and edema of the brain in 4 patients and demyelination in 1 patient, and the lesions were detected in frontal and parietal cerebrum as well as basal ganglia, unilaterally or bilaterally. Cerebrospinal fluid tests of the latter 5 patients were normal in 4 patients and increased white blood cells (mainly neutrophils initially) in 1 patient. The cerebrospinal fluid pressure was increased in 2 patients and normal in 3 patients. Cardiac involvement was found in 13 patients (10.3\%), including premature contraction in 8 , atrial tachycardia in 2 , conduction block in 2 , atrial fibrillation in 2 , valve insufficiency in 1 and pre-excitation syndrome in 1.

Associated autoimmune conditions were found in 4 patients, including 2 patients with recurrent oral ulceration, 1 patient with Sjögren's syndrome and 1 patient with IgG4 associated periorbital pseudotumor.

\section{Clinical pattern and disease evolution}

We performed correlation analysis and calculated correlation coefficients between cumulative organ involvement and found a strong negative correlation between airway involvement and auricular chondritis $(r=-0.75, P<0.001)$ and between tracheobronchial involvement and auricular chondritis $(r=-0.74$, $P<0.001)$. A weak negative correlation was found between laryngeal involvement and auricular chondritis $(r=-0.24, P=0.007)$.

We also found weak negative correlation between ocular inflammation and tracheobronchial involvement $(r=-0.32, P<0.001)$, between arthritis and tracheobronchial involvement $(r=-0.26, P=0.003)$, as well as between auricular involvement and nasal chondritis $(r=-0.20, P=0.028)$. Weak positive correlation was found between hearing loss and nasal chondritis $(r=0.36, P<0.001)$, hearing loss and cardiac involvement $(r=0.28, P=0.002)$, nasal chondritis and tracheobronchial involvement $(r=0.20, P=0.021)$, ocular inflammation and arthritis $(r=0.361, P<0.001)$, nasal involvement and myelodysplasia $(r=0.20, P=0.025)$ as well as cardiac involvement and myelodysplasia $(r=0.26, P=0.003)$. Figure 2 shows the correlationship between different organ involvement.

Based on these findings, 4 clinical patterns were identified: Ear pattern (ear involved but no airway involvement, subgroup A), Airway pattern (airway involved but no ear involvement, subgroup B), Overlap pattern (both ear and airway involved, subgroup C) and Airway-Ear negative pattern (nether auricular nor airway involved, subgroup D), which were detailed in Table 1. Apparently, Ear pattern and Airway pattern constituted the most part of RPC patients $(50.8 \%$ and $38.9 \%$ for Ear pattern and Airway pattern 
respectively at disease onset and $49.2 \%$ and $38.1 \%$ for Ear pattern and Airway pattern respectively during follow-up).

A proportion of patients with Ear pattern and Airway pattern presented with auricular chondritis and airway involvement as the sole manifestation at disease onset and during disease course, and were classified as limited RPC and the rest were classified as systemic RPC (Table 1).

After that, we analyzed the evolution of the clinical patterns from disease onset to the last visit, as detailed in Figure 3. The evolution can be summarized as follows. First, one clinical pattern can progress into another clinical pattern. Six patients with Ear pattern (3 limited form and 3 systemic form) developed airway lesions and one patient with Airway pattern developed auricular chondritis and thus they progressed into Overlap pattern. Four patients with Airway-Ear negative pattern developed auricular chondritis and progressed into Ear pattern. Second, limited RPC can progress into systemic RPC. Seven limited RPC patients with Ear pattern and 5 limited RPC patients with Airway pattern progressed into systemic disease. Third, most of the limited RPC patients ( 25 with Ear pattern and 26 with airway pattern) remained limited form during follow-up, indicating no disease progression in these patients.

\section{Clinical features compared between different patterns}

Table 2 describe the difference between RPC patients with different patterns. Because of the very few number, clinical features in patients with Airway-Ear negative pattern were merely displayed in the table but not compared with other patterns. RPC patients with Ear pattern presented with higher incidence of ocular involvement and arthritis but relative lower incidence of nasal chondritis compared with those with Airway pattern. Importantly, RPC patients with Airway pattern had higher mortality rate compared with those with Ear pattern. Interestingly, Overlap pattern seems to be a combination of Ear pattern and Airway pattern, since RPC patients with Overlap pattern presented intermediate incidence rate of ocular involvement and arthritis and mortality rate between that of those with Ear pattern and Airway pattern, but relatively higher incidence of hearing loss and nasal chondritis compared to those with Ear pattern and Airway pattern. Among 3 Airway-Ear negative pattern patients, all presented with ocular involvement and 2 presented with hearing loss, nasal chondritis, and arthritis respectively. No significant difference of age at disease onset was detected between different patterns but Ear pattern presented lower CRP level compared with Airway pattern and Overlap pattern, indicating lower inflammation of RPC patients with Ear pattern.

There were 18 deaths (14.3\%) during a median follow-up of 23.5 months (range 5-81 months), and the causes of deaths were refractory disease $(n=13)$, pulmonary infection $(n=3)$, brain tumor $(n=1)$, and unknown cause $(n=1), 1$ with ear pattern (died of brain tumor), 14 with airway pattern and 3 with overlap pattern.

The probability of survival was significantly different between Ear pattern and the other 2 patterns whereas no difference existed between Airway pattern and Overlap pattern (Figure 4). This indicates that airway involvement may be a predominant factor associated with poor prognosis. 


\section{Discussion}

The diagnosis of RPC in early stage remains challenging since the first description in 1932, even after the introduction of empirical diagnostic criteria by McAdams[14] or Damiani et al. [15] and Michet et al . [16]. Due to lack of the development of new criteria aiming for early diagnosis, being aware of clinical patterns and disease evolution may help clinicians to diagnose this rare disease in early stage. Herein, we report a retrospective cohort of 126 RPC patients with description of the clinical features and defined 4 clinical patterns and 2 presenting forms (limited and systemic forms) and described the disease evolution during follow-up.

Most of our patients (69.1\%) did not meet with the traditional criteria when diagnoses were established, which may indicate that patients not meeting with the traditional criteria is quite common in Chinese patients and that traditional criteria are not suitable to diagnose majority of RPC patients especially partial RPC and limited RPC. Interestingly, 5 patients did not meet with neither traditional criteria nor partial or limited RPC, since cardiac involvement and neurological involvement were not the items included in these proposed criteria.

Cumulative features of large case series were summarized in Supplementary Table S1 and most series were about Caucasians. Patients from different regions may manifest with distinct features. The age at diagnosis of our patients was comparable to previous reports. The diagnostic delay was much shorter than previous study, indicating more RPC patients in early stage were included in our study. Comparable airway involvement but lower frequency of other features were observed, which may be due to the shorter follow-up period of our study. Meanwhile, it also demonstrated relatively more severe disease in Chinese population, since more patients in our cohort developed airway involvement in a relatively short follow-up duration compared with other reports. In concordance with Lin's findings [7], the patients in our study had a higher initial frequency of laryngo-tracheal involvement (42.9\%) than the Caucasians (14-38\% initially), again demonstrating more severe disease in Chinese population, consistent with the observations made by Kong et al.[31].

Clinical classification is of vital importance to for early diagnosis. The French study by Dion et al. [27] classified the disease into three clinical subtypes: hematologic (with the worst prognosis), respiratory and mild phenotype based on disease severity, progression and prognosis. However, this classification seems not to be helpful to improve clinicians' vigilance for early diagnosis. Correlation analysis of 239 cases by Shimizu et al. [28] showed that a strong negative correlation exists between airway involvement and external ear involvement $(r=-0.48)$. Therefore, the disease was divided into three clinical subgroups[29]: airway involvement (47 cases), external ear involvement (118 cases) and both airway and external ear involvement (70 cases). However, this study did not include limited RPC and partial RPC. The re-analysis of the cohort data by French scholars also found a negative correlation between tracheobronchial involvement and external ear involvement $(r=-0.245, P=0.003)$ but not the airway overall[32].

By correlation analysis, However, our current study demonstrated a much stronger negative correlation between airway involvement and auricular chondritis $(r=-0.754, P<0.001)$ than that of Japanese and 
French studies by Shimizu et al [28, 29] and Dion et al. [32]. Based on these findings, we divided RPC patients into 4 clinical patterns: Ear pattern (Subgroup A), Airway pattern (Subgroup B), Overlap pattern (Subgroup C) and Airway-Ear negative pattern (Subgroup D). The fact that patients with Ear pattern had the best prognosis and relative lower inflammatory status further suggests that patients with ear involvement can be a distinct clinical pattern. Ear pattern and Airway pattern had the largest number of patients, while Overlap pattern and Airway-Ear negative pattern had a relatively small number of patients. However, the clinical pattern did not remain unchanged during follow-up. Ear pattern and Airway pattern may progress into Overlap pattern and Airway-Ear negative pattern may progress into ear pattern while limited form may progress into systemic form, which reflected the progression of the disease. Particular attention should be paid to that a small number of patients with Ear pattern can progress into Overlap pattern, indicating a severe progression leading to disastrous consequences. The analysis of clinical characteristics of different patterns indicated the relationship between auricular chondritis and ocular inflammation and arthritis, and relationship between airway involvement and nasal chondritis, which reflect different disease pathogenesis between different clinical patterns.

Patients with laryngo-tracheal manifestation or auricular inflammation as the only initial feature of the disease[13], sometimes as the sole feature [8, 17-24], have been defined as limited form of RPC. In our cohort, $47.6 \%$ of the patients presented as limited RPC initially and $45.2 \%$ remained limited form during follow-up, suggesting that the limited RPC is not uncommon among Chinese patients. The concept of limited and systemic form is also supported by a recent online survey conducted by US authors[8] but with much lower incidence of limited RPC (16 and 2 out of 304 patients presented as isolated ear involvement and isolated airway involvement respectively).

There are some limitations of our study. First, the retrospective analysis of the hospitalized patients can miss some out-clinic patients causing incomplete inclusion of clinical features. Second, the relatively short follow-up duration may underestimate the frequency of organ involvements. But our study also has some strengthens. First, we include RPC patients in early stage because the diagnostic delay was much shorter than previous study which may facilitate early recognition of RPC. Second, we included partial RPC and limited RPC and further strengthen the consensus that new classification criteria should be put on agenda.

In conclusion, our study included early RPC patients, defined distinct characteristics of Chinese RPC patients and categorized them into 4 different clinical patterns and 2 distinct presenting forms (limited and systemic forms) which may facilitate early recognition of this rare disease. In addition, we believe our study may contribute to an updated classification criteria covering all the clinical spectrum of RPC.

\section{Abbreviations}

RPC, relapsing polychondritis; ANCA, anti-neutrophilic cytoplasmic antibody; ENT, ear, nose, and throat; OR, Odds Ratio 


\section{Declarations}

\section{Ethics approval and consent to participate}

This study was approved by the Ethic Committee of Zhengzhou University (SR-2018-LW-050) and was conducted in accordance with the Declaration of Helsinki.

\section{Consent for publication}

In this manuscript, individual patient data are not presented.

\section{Availability of data and materials}

All data generated or analysed during this study are included in this published article [and its supplementary information files].

\section{Competing interests}

The authors declare no conflict of interest.

\section{Funding}

No specific funding was received from any bodies in the public, commercial or not-for-profit sectors to carry out the work described in this article.

Author Contributions: Lei Zhang, Shengyun Liu and Tianfang Li designed the study; Lei Zhang, Shuang Yun囚Tiange Wu, Yujie He, Jinyan Guo, Lishuai Han,Jiameng Lu, Xiaojun Liu, Rui Yang and Shitao Zhang collected the data; Lei Zhang and Shuang Yun analyzed data, performed statistical analysis and wrote the manuscript; Tianfang Li revised the manuscript. All authors read and approved the final manuscript.

Acknowledgements

We thank our colleagues for their assistance in data collection and analysis.

\section{References}

1. Lahmer T, Treiber M, von Werder A, Foerger F, Knopf A, Heemann U, Thuermel K: Relapsing polychondritis: An autoimmune disease with many faces. Autoimmun Rev 2010, 9(8):540-546.

2. Rednic S, Damian L, Talarico R, Scire CA, Tobias A, Costedoat-Chalumeau N, Launay D, Mathian A, Mattews L, Ponte $\mathrm{C}$ et al: Relapsing polychondritis: state of the art on clinical practice guidelines. RMD Open 2018, 4(Suppl 1):e000788.

3. Kingdon J, Roscamp J, Sangle S, D'Cruz D: Relapsing polychondritis: a clinical review for rheumatologists. Rheumatology (Oxford) 2018, 57(9):1525-1532.

4. Kent PD, Michet CJ, Jr., Luthra HS: Relapsing polychondritis. Curr Opin Rheumato/ 2004, 16(1):56-61. 
5. Hazra N, Dregan A, Charlton J, Gulliford MC, D'Cruz DP: Incidence and mortality of relapsing polychondritis in the UK: a population-based cohort study. Rheumatology (Oxford) 2015, 54(12):2181-2187.

6. Zhang L, Wu TG, He YJ, Guo JY, Han LS, Lu JM, Liu SY, Li TF: Diagnosing relapsing polychondritis remains a common challenge: experience from a Chinese retrospective cohort. Clin Rheumatol 2020.Ahead of print

7. Lin D-F, Yang W-Q, Zhang P-P, Lv Q, Jin O, Gu J-R: Clinical and prognostic characteristics of 158 cases of relapsing polychondritis in China and review of the literature. Rheumatology International 2016, 36(7):1003-1009.

8. Ferrada MA, Grayson PC, Banerjee S, K AS, R AC, Sinaii N, Katz JD: Patient Perception of DiseaseRelated Symptoms and Complications in Relapsing Polychondritis. Arthritis Care Res (Hoboken) 2018, 70(8):1124-1131.

9. Zeuner M, Straub RH, Rauh G, Albert ED, Scholmerich J, Lang B: Relapsing polychondritis: clinical and immunogenetic analysis of 62 patients. J Rheumato/ 1997, 24(1):96-101.

10. Belot A, Duquesne A, Job-Deslandre C, Costedoat-Chalumeau N, Boudjemaa S, Wechsler B, Cochat P, Piette JC, Cimaz R: Pediatric-onset relapsing polychondritis: case series and systematic review. $J$ Pediatr 2010, 156(3):484-489.

11. Mathew SD, Battafarano DF, Morris MJ: Relapsing polychondritis in the Department of Defense population and review of the literature. Semin Arthritis Rheum 2012, 42(1):70-83.

12. Sharma A, Law AD, Bambery P, Sagar V, Wanchu A, Dhir V, Vijayvergiya R, Sharma K, Gupta A, Panda NK et al: Relapsing polychondritis: clinical presentations, disease activity and outcomes. Orphanet Journal of Rare Diseases 2014, 9(1).

13. Trentham DE, Le CH: Relapsing polychondritis. Ann Intern Med 1998, 129(2):114-122.

14. McAdam LP, O'Hanlan MA, Bluestone R, Pearson CM: Relapsing polychondritis: prospective study of 23 patients and a review of the literature. Medicine (Baltimore) 1976, 55(3):193-215.

15. Damiani JM, Levine HL: Relapsing polychondritis-report of ten cases. Laryngoscope 1979, 89(6 Pt 1):929-946.

16. Michet CJ, Jr., McKenna CH, Luthra HS, O'Fallon WM: Relapsing polychondritis. Survival and predictive role of early disease manifestations. Ann Intern Med 1986, 104(1):74-78.

17. Higenbottam T, Dixon J: Chondritis associated with fatal intramural bronchial fibrosis. Thorax 1979, 34(4):563-564.

18. Coppola M, Yealy DM: Relapsing polychondritis: an unusual cause of painful auricular swelling. Ann Emerg Med 1992, 21(1):81-85.

19. Sheffield E, Corrin B: Fatal bronchial stenosis due to isolated relapsing chondritis. Histopathology 1992, 20(5):442-443.

20. Ozbay B, Dilek FH, Yalcinkaya I, Gencer M: Relapsing polychondritis. Respiration 1998, 65(3):206207. 
21. Ernst A, Rafeq S, Boiselle P, Sung A, Reddy C, Michaud G, Majid A, Herth FJF, Trentham D: Relapsing polychondritis and airway involvement. Chest 2009, 135(4):1024-1030.

22. Maimon N, Lee P, Paul N, Hwang D, Marras TK, Keshavjee S, Chan CK: Tracheobronchial involvement as a sole manifestation of relapsing polychondritis. J Bronchology Interv Pulmonol 2010, 17(1):5-10.

23. Suzuki S, Ikegami A, Hirota Y, Ikusaka M: Fever and cough without pulmonary abnormalities on CT: relapsing polychondritis restricted to the airways. Lancet 2015, 385(9962):88.

24. Alqanatish JT, Alfarhan BA, Qubaiban SM: Limited auricular relapsing polychondritis in a child treated successfully with infliximab. BMJ Case Rep 2019, 12(5).

25. Bachor E, Blevins NH, Karmody C, Kuhnel T: Otologic manifestations of relapsing polychondritis. Review of literature and report of nine cases. Auris Nasus Larynx 2006, 33(2):135-141.

26. Yang $H$, Peng $L$, Jian M, Qin L: Clinical analysis of 15 patients with relapsing auricular polychondritis. Eur Arch Otorhinolaryngol 2014, 271(3):473-476.

27. Dion J, Costedoat-Chalumeau N, Sene D, Cohen-Bittan J, Leroux G, Dion C, Frances C, Piette JC: Relapsing Polychondritis Can Be Characterized by Three Different Clinical Phenotypes: Analysis of a Recent Series of 142 Patients. Arthritis Rheumato/ 2016, 68(12):2992-3001.

28. Shimizu J, Yamano Y, Yudoh K, Suzuki N: Organ Involvement Pattern Suggests Subgroups Within Relapsing Polychondritis: Comment on the Article by Dion et al. Arthritis \& Rheumatology 2018, 70(1):148-149.

29. Shimizu J, Yamano Y, Kawahata K, Suzuki N: Relapsing polychondritis patients were divided into three subgroups: patients with respiratory involvement (R subgroup), patients with auricular involvement (A subgroup), and overlapping patients with both involvements ( 0 subgroup), and each group had distinctive clinical characteristics. Medicine (Baltimore) 2018, 97(42):e12837.

30. Piette JC, Dion J, Costedoat-Chalumeau N: News on Relapsing Polychondritis: The Patient's Experience. Arthritis Care Res (Hoboken) 2018, 70(8):1121-1123.

31. Kong KO, Vasoo S, Tay NS, Chng HH: Relapsing polychondritis--an Oriental case series. Singapore Med J 2003, 44(4):197-200.

32. Dion J, Costedoat-Chalumeau N, Piette J-C: Reply. Arthritis \& Rheumatology 2018, 70(1):149-149.

\section{Tables}

Table 1 Classification based on organ involvement pattern*

\begin{tabular}{|c|c|c|c|c|c|c|}
\hline & \multicolumn{2}{|c|}{ Organ involvement } & \multicolumn{2}{|c|}{ At disease onset } & \multicolumn{2}{|c|}{ During follow-up } \\
\hline & Ear & Airway & Limited & Systemic & Limited & Systemic \\
\hline Subgroup A & + & - & $35(27.8)$ & $29(23.0)$ & $25(19.8)$ & $37(29.4)$ \\
\hline Subgroup B & - & + & $31(24.6)$ & 18(14.3) & $26(20.6)$ & $22(17.5)$ \\
\hline Subgroup C & + & + & $0(0)$ & $6(4.8)$ & $0(0)$ & 13(10.3) \\
\hline Subgroup D & - & - & $0(0)$ & $7(5.6)$ & $0(0)$ & $3(2.4)$ \\
\hline
\end{tabular}


*Data are presented as n (\%).

Table 2 Different characteristics of 4 clinical patterns.

\begin{tabular}{|c|c|c|c|c|c|c|c|c|}
\hline \multirow[t]{2}{*}{ Variables } & $\begin{array}{l}\text { Subgroup } \\
\text { A }\end{array}$ & Subgroup B & Subgroup C & Subgroup D & \multirow[b]{2}{*}{$\begin{array}{c}\text { A vs B vs } \\
\text { C } \\
\text { P value }\end{array}$} & \multirow[b]{2}{*}{$\begin{array}{l}\text { A vs B } \\
\mathrm{P} \\
\text { value }\end{array}$} & \multirow[b]{2}{*}{$\begin{array}{l}\text { A vs } \mathrm{C} \\
\mathrm{P} \\
\text { value }\end{array}$} & \multirow[b]{2}{*}{$\begin{array}{l}\mathrm{B} \text { vs } \mathrm{C} \\
\mathrm{P} \\
\text { value } \\
\end{array}$} \\
\hline & $\begin{array}{l}\text { Ear } \\
\text { pattern } \\
(\mathrm{n}=62)\end{array}$ & $\begin{array}{l}\text { Airway } \\
\text { pattern } \\
(\mathrm{n}=48)\end{array}$ & $\begin{array}{l}\text { Overlap } \\
\text { pattern } \\
(\mathrm{n}=13)\end{array}$ & $\begin{array}{l}\text { A-E }(-) \\
\text { pattern* } \\
(n=3)\end{array}$ & & & & \\
\hline \multicolumn{9}{|l|}{ Organ involvement } \\
\hline Auricular chondritis, \% & 100 & 0 & 100 & 0 & $<0.001$ & $<0.001$ & 1 & $<0.001$ \\
\hline Hearing loss, \% & 9.7 & 8.3 & 23.1 & 66.7 & 0.293 & 1.000 & 0.183 & 0.159 \\
\hline Nasal chondritis, \% & 6.5 & 25 & 30.8 & 66.7 & 0.011 & 0.012 & 0.027 & 0.728 \\
\hline Ocular inflammation, \% & 38.7 & 8.3 & 23.1 & 100 & 0.001 & $<0.001$ & 0.355 & 0.159 \\
\hline Arthritis, \% & 27.4 & 4.2 & 15.4 & 66.7 & 0.006 & 0.002 & 0.496 & 0.196 \\
\hline Airway involvement, \% & 0 & 100 & 100 & 0 & $<0.001$ & $<0.001$ & $<0.001$ & l \\
\hline Tracheobronchial, \% & 0 & 89.6 & 61.5 & 0 & $<0.001$ & $<0.001$ & $<0.001$ & 0.028 \\
\hline Laryngeal, \% & 0 & 27.1 & 46.2 & 0 & $<0.001$ & $<0.001$ & $<0.001$ & 0.311 \\
\hline Fever, \% & 19.4 & 22.9 & 15.4 & 33.3 & 0.806 & 0.649 & 1.000 & 0.715 \\
\hline Costachondritis, \% & 3.2 & 10.4 & 0 & 0 & 0.175 & 0.236 & 1.000 & 0.575 \\
\hline Skin involvement, \% & 1.6 & 2.1 & 0 & 0 & 0.870 & 1.000 & 1.000 & 1.000 \\
\hline $\begin{array}{l}\text { Neurological } \\
\text { manifestation, \% }\end{array}$ & 6.5 & 2.1 & 0 & 0 & 0.379 & 0.384 & 1.000 & 1.000 \\
\hline Cardiac manifestation, \% & 12.9 & 8.3 & 7.8 & 0 & 0.696 & 0.546 & 1.000 & 1.000 \\
\hline Myelodysplasia, \% & 1.6 & 0 & 0 & 0 & 0.609 & 1.000 & 1.000 & 1 \\
\hline Deaths, \% & 1.6 & 29.2 & 23.1 & 0 & $<0.001$ & 0.015 & $<0.001$ & 1.000 \\
\hline $\begin{array}{l}\text { Age at onset, mean } \pm \mathrm{SD} \text {, } \\
\text { years }\end{array}$ & $46.6 \pm 14.4$ & $48.2 \pm 12.7$ & $45.0 \pm 15.5$ & $46.3 \pm 16.6$ & 0.715 & 0.559 & 0.698 & 0.460 \\
\hline ESR, median (range), $\mathrm{mm} / \mathrm{h}$ & $15(0-166)$ & $53.5(0-127)$ & $25(2-90)$ & $53(21-95)$ & 0.234 & 0.136 & 0.215 & 0.993 \\
\hline $\mathrm{CRP}$, median (range), $\mathrm{mg} / \mathrm{L}$ & $\begin{array}{l}7.7(0- \\
116.3)\end{array}$ & $\begin{array}{c}36.1(0.2- \\
165.0)\end{array}$ & $24.0(1.5-95.9)$ & $\begin{array}{c}12.7(9.9- \\
105.0)\end{array}$ & 0.003 & 0.002 & 0.023 & 0.652 \\
\hline
\end{tabular}

Note: The colour depth of each cell is proportional to the percentage of patients with the specific features. P-values in boldface indicate statistical significance $(\mathrm{P}<0.05)$. Airway-Ear (-) pattern was not compared with other patterns, due to limited number of patients.

* A-E (-) pattern: Airway-Ear negative pattern; 


\section{Figures}

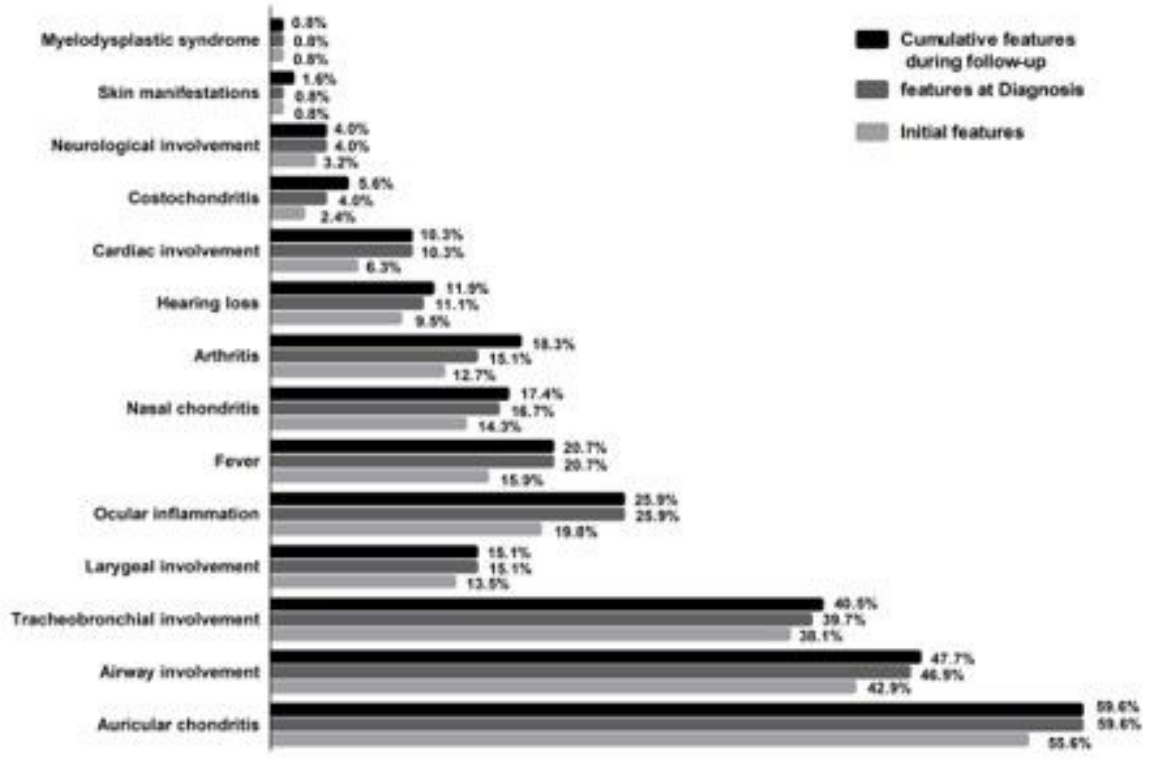

\section{Figure 1}

Features of relapsing polychondritis patients in our cohort at disease onset, diagnosis and during followup.

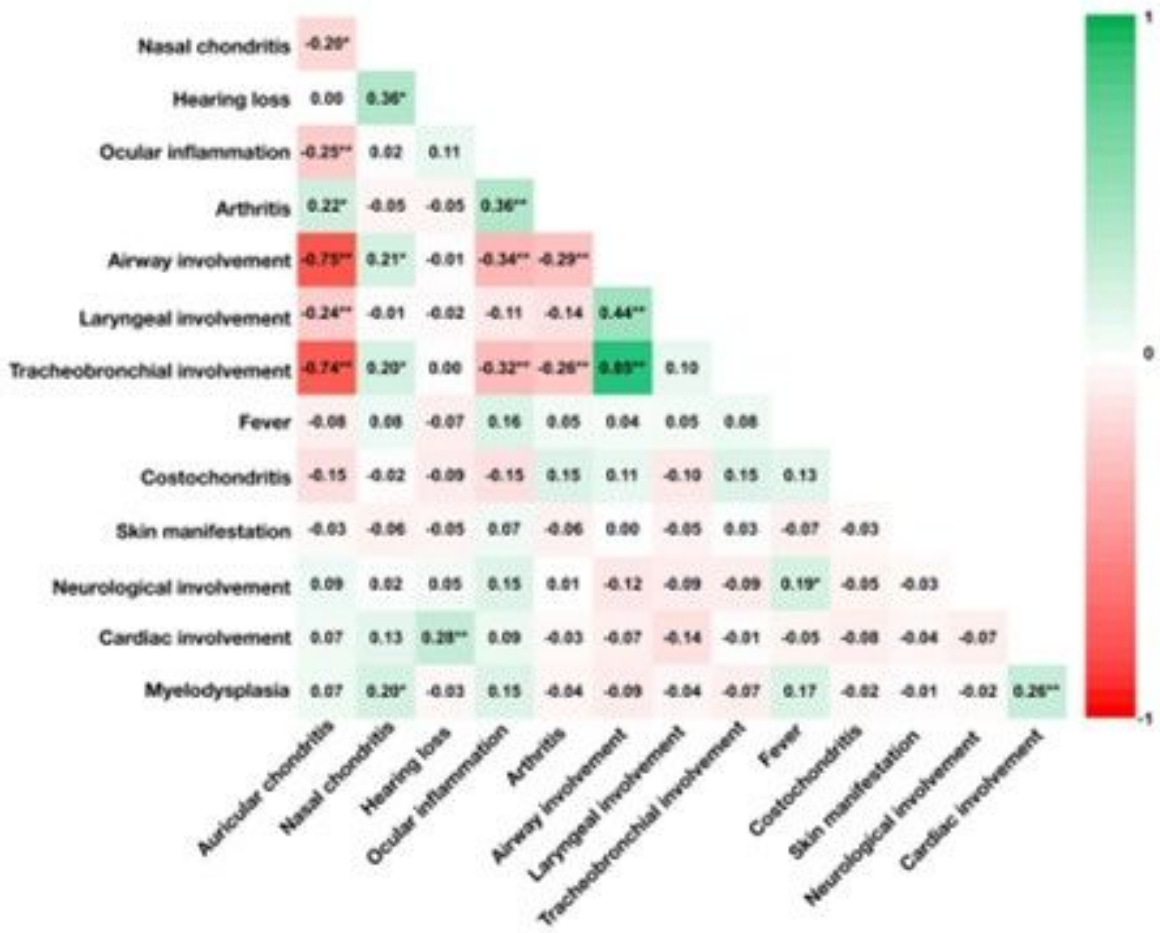

Figure 3 
Correlation analysis of different organ involvement. The colour depth is proportional to correlation strength, and red represent negative correlation while green represent positive correlation. ${ }^{\star} P<0.05$; ** $\mathrm{P}<0.01$.

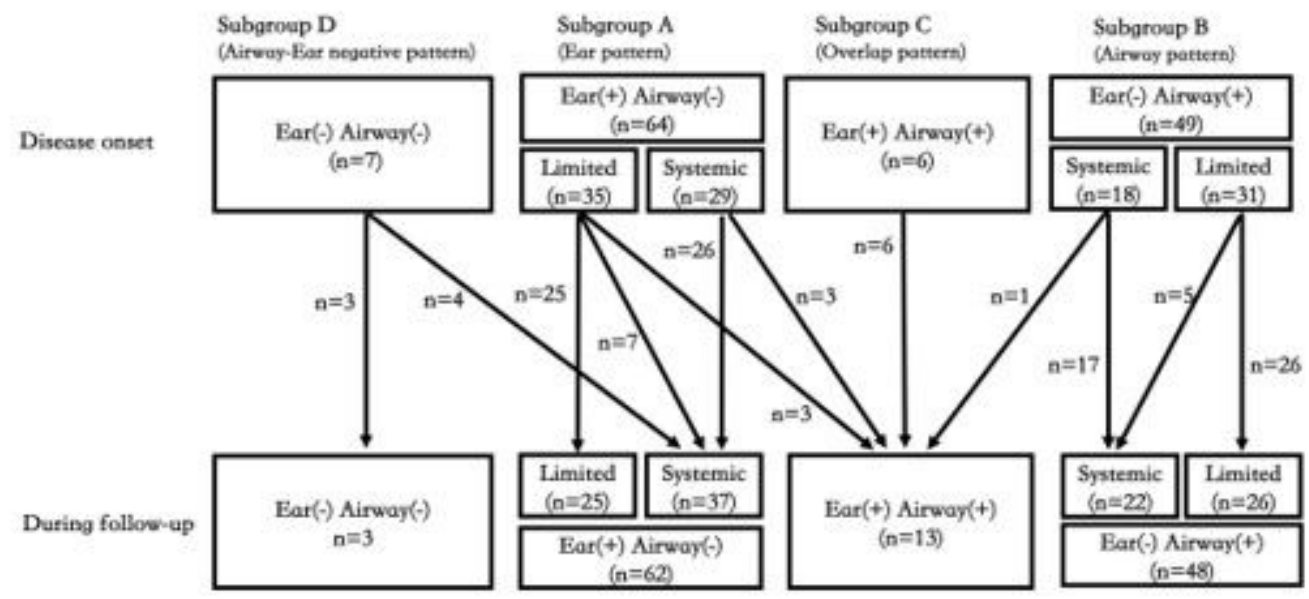

\section{Figure 6}

The evolution of clinical patterns and presenting forms from disease onset to last visit.

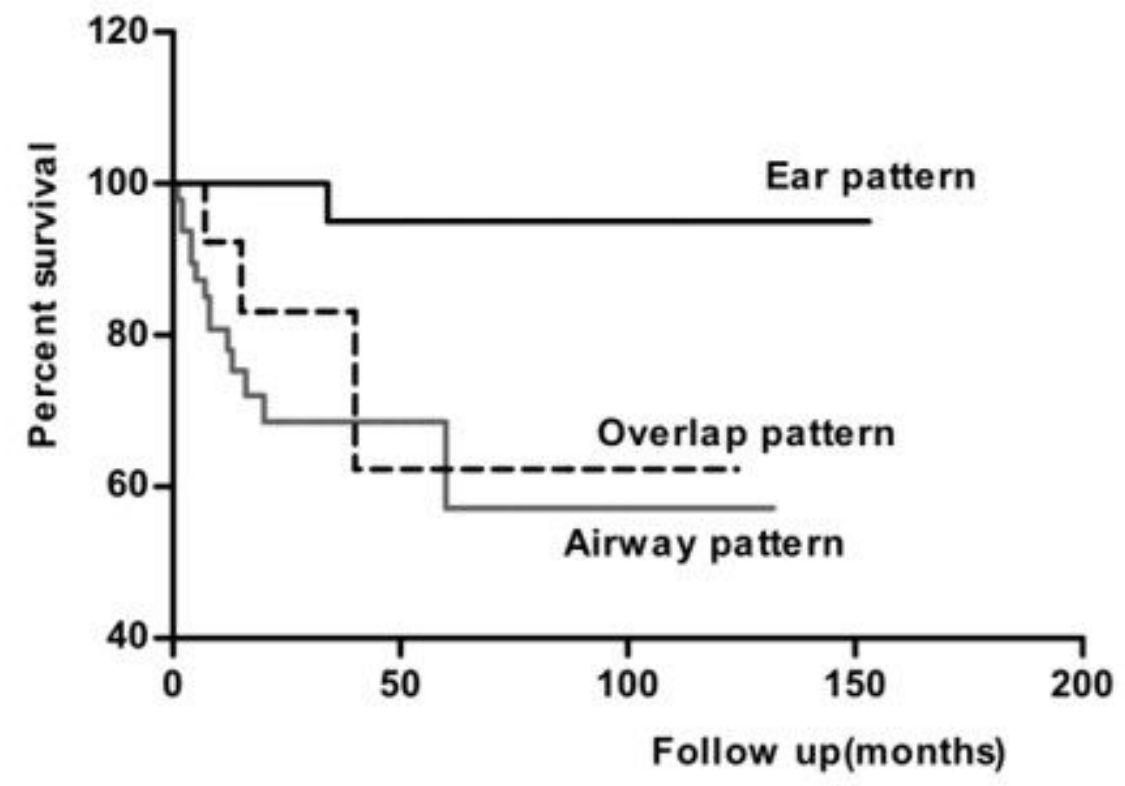

Figure 8

Survival curve of Ear pattern, Airway pattern and Overlap pattern. Log Rank tests, overall $P<0.001$; Ear pattern vs Airway pattern $\mathrm{P}<0.001$; Ear pattern vs Overlap pattern $\mathrm{P}=0.005$; Airway pattern vs Overlap pattern $\mathrm{P}=0.587$. 


\section{Supplementary Files}

This is a list of supplementary files associated with this preprint. Click to download.

- Supplementarymaterials.docx

- Supplementarymaterials.docx 